\title{
Involvement of DNA Polymerase Beta in Repair of Ionizing Radiation Damage as Measured by In Vitro Plasmid Assays
}

Author(s): Conchita Vens, Ingrid Hofland, Adrian C. Begg

Source: Radiation Research, 168(3):281-291. 2007.

Published By: Radiation Research Society

DOI: http://dx.doi.org/10.1667/RR0750.1

URL: http://www.bioone.org/doi/full/10.1667/RR0750.1

BioOne (www.bioone.org) is a nonprofit, online aggregation of core research in the biological, ecological, and environmental sciences. BioOne provides a sustainable online platform for over 170 journals and books published by nonprofit societies, associations, museums, institutions, and presses.

Your use of this PDF, the BioOne Web site, and all posted and associated content indicates your acceptance of BioOne's Terms of Use, available at www.bioone.org/page/terms_of_use.

Usage of BioOne content is strictly limited to personal, educational, and non-commercial use. Commercial inquiries or rights and permissions requests should be directed to the individual publisher as copyright holder. 


\title{
Involvement of DNA Polymerase Beta in Repair of lonizing Radiation Damage as Measured by In Vitro Plasmid Assays
}

\author{
Conchita Vens, Ingrid Hofland and Adrian C. Begg ${ }^{1}$ \\ Division of Experimental Therapy, The Netherlands Cancer Institute, Plesmanlaan 121, 1066 CX Amsterdam, The Netherlands
}

\begin{abstract}
Vens, C., Hofland, I. and Begg, A. C. Involvement of DNA Polymerase Beta in Repair of Ionizing Radiation Damage as Measured by In Vitro Plasmid Assays. Radiat. Res. 168, 281291 (2007).
\end{abstract}

Characteristic of damage introduced in DNA by ionizing radiation is the induction of a wide range of lesions. Singlestrand breaks (SSBs) and base damages outnumber doublestrand breaks (DSBs). If unrepaired, these lesions can lead to DSBs and increased mutagenesis. XRCC1 and DNA polymerase beta $(\operatorname{pol} \beta)$ are thought to be critical elements in the repair of these SSBs and base damages. XRCC1-deficient cells display a radiosensitive phenotype, while proliferating pol $\beta$ deficient cells are not more radiosensitive. We have recently shown that cells deficient in pol $\beta$ display increased radiosensitivity when confluent. In addition, cells expressing a dominant negative to pol $\beta$ have been found to be radiosensitized. Here we show that repair of radiation-induced lesions is inhibited in extracts with altered pol $\beta$ or XRCC1 status, as measured by an in vitro repair assay employing irradiated plasmid DNA. Extracts from XRCC1-deficient cells showed a dramatically reduced capacity to repair ionizing radiation-induced DNA damage. Extracts deficient in pol $\beta$ or containing a dominant negative to pol $\beta$ also showed reduced repair of radiation-induced SSBs. Irradiated repaired plasmid DNA showed increased incorporation of radioactive nucleotides, indicating use of an alternative long-patch repair pathway. These data show a deficiency in repair of ionizing radiation damage in extracts from cells deficient or altered in pol $\beta$ activity, implying that increased radiosensitivity resulted from radiation damage repair deficiencies. $\odot 2007$ by Radiation Research Society

\section{INTRODUCTION}

Making use of the destructive nature of ionizing radiation, radiotherapy has developed into a potent and widely used modality in cancer treatment, with cellular radioresistance posing a limiting factor in treatment outcome. A better understanding of how cells respond to and repair radiation damage is necessary. Exposure of cells to ionizing

\footnotetext{
${ }^{1}$ Address for correspondence: Division of Experimental Therapy, The Netherlands Cancer Institute, Plesmanlaan 121, 1066 CX Amsterdam, The Netherlands; e-mail: a.begg@nki.nl.
}

radiation results in formation of a wide range of damages to DNA. Double-strand breaks are thought to be the most lethal type of damage, and consequently DSB repair has been examined extensively. Less attention has been given to the repair of ionizing radiation-induced base damages and single-strand breaks (SSBs), although they are induced at much higher yields. If unrepaired, these damages will result in additional double-strand breaks and/or an increased rate of mutagenesis.

DNA damage resulting from either oxidative damage or exposure to alkylating drugs, like base and sugar damages and abasic sites, is repaired primarily by the base excision repair (BER) pathway (1). BER is initiated by the removal of the damaged base by specific glycosylases, which remove damaged bases from DNA by cleavage of the $N$ glycosylic bond between base and deoxyribose. The resulting abasic site is incised by an AP endonuclease, resulting in the formation of nicked DNA intermediates with a $5^{\prime}$-dRP moiety (deoxyribose phosphate) and a $3^{\prime}$-phosphate end. Removal of this moiety is attributed to the dRP lyase activity of DNA polymerase $\beta$. Alternatively, base excision by bifunctional glycosylase generate next to the glycosylic bond cleavage a single-strand break with $5^{\prime}$ phosphate and $3^{\prime}-\alpha, \beta$ unsaturated aldehyde. AP endonuclease (APE) incises the DNA backbone next to the abasic product generated by the glycosylase action to allow a DNA polymerase to fill the gap. Synthesis is followed by ligation and resealing of the DNA. Base excision repair proceeds by two alternative pathways: Replacement of one nucleotide defines the short patch repair subpathway of BER performed by DNA polymerase $\beta$, while incorporation of several nucleotides leading to longer stretches of newly synthesized DNA is called the long patch pathway. This latter pathway is thought to be dependent on PCNA, and DNA polymerase $\beta$ as well as the replicative DNA polymerases delta/epsilon have been described to be involved $(2,3)$. Ligase III bound to XRCC1 closes the remaining nick in the short patch repair subpathway, whereas long patch repair seems to mostly use Ligase I (XRCC1 independent) (4).

One of the first proteins to be implicated in single-strand break repair was XRCC1, originally found to complement radiation sensitivity in the mutant hamster cell line EM9 
(5). Further studies showed increased sensitivity to several DNA-damaging agents and impairment of SSB rejoining by alkaline comet analysis. In in vitro repair assays applying oligonucleotides to purified proteins, Whitehouse et al. then showed that single-strand break repair required XRCC1 and DNA polymerase $\beta$ (6).

Most in vitro assays that led to the development of repair models for base excision and single-strand break repair have used short oligonucleotides or circular DNA with well-defined DNA lesions. For damages relevant to ionizing radiation, these are 7,8-dihydro-8-oxo-2'-deoxyguanosine (8-OxoG), formaminopyrimidine (Fapy), abasic sites, single-strand breaks and thymine glycol derivatives. All these studies showed the critical role of DNA polymerase $\beta$ and XRCC1 in repair of these lesions (7-14). Cells deficient in XRCC1 are radiosensitive, and the involvement of XRCC1 in base excision repair and single-strand break repair has been underlined in many cellular studies. The radiosensitive phenotype has been attributed mainly to its role as a "nick sensor", initiating single-strand break repair and to the concomitantly reduced Ligase III. DNA polymerase $\beta$-deficient cells are highly sensitive to alkylating damage, confirming its role in base excision repair. However, in contrast to XRCC1, proliferating pol $\beta$-deficient cells do not exhibit a radiosensitive phenotype $(15,16)$. To date, the sole experimental data to support its involvement in cellular resistance to ionizing radiation come from studies with a dominant negative to DNA polymerase $\beta$ (17). Recent data from our group demonstrated hypersensitivity of cells deficient in pol $\beta$ to ionizing radiation, but only when they were nonproliferating under confluent conditions (18). We therefore questioned whether base excision and single-strand break repair after exposure to ionizing radiation is inhibited by altered DNA polymerase $\beta$ status.

Ionizing radiation induces a broad range of types of lesion, leading to a high complexity of DNA damage. Some are few in number and are potentially difficult to repair, while others, although abundant, may not represent the critical rate-limiting factor in overall repair. In addition, some lesions if not repaired or if repaired slowly might not be cytotoxic and thereby would not contribute to survival. In addition to base and sugar lesions, nicked BER intermediates and directly induced SSBs are formed with non-ligatable ends that require further processing. In vitro assays with specific individual lesions could therefore overestimate the involvement of specific repair proteins and pathways. We therefore applied an in vitro plasmid assay that allows the monitoring of repair of genuine radiation-induced lesions. In this assay, described previously by Satoh and Lindahl (19), DNA is irradiated prior to application of the repair assay. The DNA is then subjected to cell extracts proficient or deficient in XRCC1 or DNA polymerase $\beta$, rather than to purified proteins, to allow evaluation of their role in the context of possible alternative backup pathways (20).

We also used cell extracts from cells expressing a dom- inant negative to DNA polymerase $\beta$. We have shown previously that expression of this dominant negative, consisting of a 14-kDa DNA binding domain of DNA polymerase $\beta$ (pol $\beta D N)$, resulted in radiosensitization $(17,21)$. We further demonstrated that radiosensitization was dependent on XRCC1 but not on DNA polymerase $\beta$ itself (22). We postulated that this resulted from the concomitant inhibition of repair by the wild-type polymerase and alternative backup pathways active in pol $\beta$-deficient cells. The dominant negative is thought to interact physically with base excision/ single-strand break repair DNA intermediates, thus blocking access of DNA polymerase $\beta$ and other enzymes to the lesion. By directly analyzing repair on irradiated DNA in vitro, we attempted to confirm BER and SSB repair inhibition of the DNA polymerase $\beta$ dominant negative on genuine radiation-induced lesions.

\section{MATERIALS AND METHODS}

\section{Cell Culture and Reagents}

The A549-LZRS and A549-polßDN cells were derived from the A549 (human adenocarcinoma) cell line that has been transduced either with an empty LZRS-IRES-EGFP vector as control or carrying a truncated DNA polymerase $\beta$ construct as described previously (17). Cells of the wild-type mouse embryonic fibroblast cell line Mß16tsA (wild-type MEF) and the matched littermate polymerase $\beta$ null cell line M $\beta 19$ tsA (polßKO MEF) were kindly provided by S. H. Wilson (NIH). Cells were cultured under standard conditions as monolayers in DMEM supplemented with $10 \% \mathrm{FCS}$ at $37^{\circ} \mathrm{C}$ in a $95 \%$ air $/ 5 \% \mathrm{CO}_{2}$ humidified atmosphere. XRCC1-deficient EM9 cells and their corresponding AA8 parental cells were purchased from ATTC (American Type Culture Collection, Manassas, VA) and were grown in F10 medium.

\section{Preparation of Cell Extracts}

Cell extracts were prepared using a modified version of the procedure originally described by Tanaka $e t$ al. (23) and later adapted by Biade $e t$ al. (24). Briefly, exponentially growing cells were washed with ice-cold PBS and resuspended in buffer I (10 $\mathrm{m} M$ Tris- $\mathrm{HCl}, \mathrm{pH} 7.8,200 \mathrm{~m} M$ $\mathrm{KCl})$. Cells were lysed by addition of an equal volume of buffer II [10 $\mathrm{m} M$ Tris-HCl, pH 7.8, $200 \mathrm{~m} M \mathrm{KCl}, 2 \mathrm{~m} M$ EDTA, 40\% (v/v) glycerol, $0.2 \%$ (v/v) Nonidet P-40, $2 \mathrm{~m} M$ dithiotreitol (DTT), $0.5 \mathrm{~m} M$ phenylmethylsulfonyl fluoride (PMSF), $10 \mu \mathrm{g} / \mathrm{ml}$ aprotinin, $5 \mu \mathrm{g} / \mathrm{ml}$ leupeptin, $1 \mu \mathrm{g} / \mathrm{ml}$ pepstatin] to the cell suspension and shaking for $1.5 \mathrm{~h}$ at $4^{\circ} \mathrm{C}$. Cells were centrifuged at $16,000 \mathrm{~g}$, and the supernatant was recovered, divided into aliquots and stored at $-80^{\circ} \mathrm{C}$. Protein levels were assessed by PAGE and immunoblotting $[\alpha-\operatorname{pol} \beta$ (18S) and $\alpha$-XRCC1 (33-2-5) NeoMarkers from Lab Vision, Fremont, CA; $\alpha$-tubulin (TU-02) from Santa Cruz, Biotechnology, Santa Cruz, CA].

\section{Preparation of Plasmid DNA Substrate}

The 3-kb plasmid pGEM-5Zf(+) (Promega) was isolated after propagation in DH5 $\alpha$ using a Qiagen plasmid purification kit (Westburg). Closed circular plasmid DNA was resuspended in $10 \mathrm{mM}$ Tris- $\mathrm{HCl}, \mathrm{pH}$ 8.5, and exposed to $50 \mathrm{~Gy}$ of $\mathrm{X}$ rays (dose rate of $1 \mathrm{~Gy} / \mathrm{min}$ ) from a ${ }^{137} \mathrm{Cs}$ source at $0^{\circ} \mathrm{C}$. Under these conditions, half of the DNA was open circular plasmid as determined after gel electrophoresis $\left(20^{\circ} \mathrm{C}\right)$ and thus contained an average of one nick per molecule (Fig. 1). Unirradiated DNA remained closed as determined by gel electrophoresis, demonstrating that nicks occurred after irradiation with minimal contribution from non-radiation-related oxidative damage. Nicks in the irradiated DNA are a result of prompt SSBs and secondary nicks formed at radiation-induced 


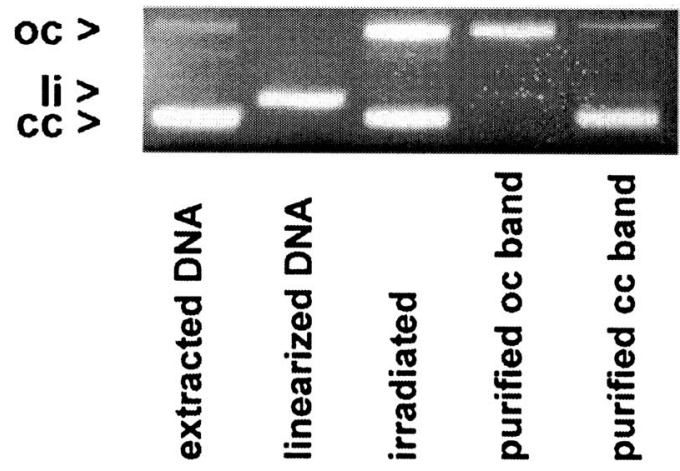

FIG. 1. Irradiated plasmid DNA as substrate for the in vitro repair assays. Preparation of plasmid DNA resulted in closed circular (cc) plasmid DNA with little formation of open circular (oc) or linear (li) DNA (first lane). DNA linearized by enzymatic restriction to visualize linear plasmid DNA position (second lane). Irradiation of the extracted DNA resulted in the induction of nicks and increase in the open circle plasmid DNA band. Open circular DNA was extracted and purified from gels with little loss. Simultaneous purification of the closed circular DNA band showed little induction of nicks or DSBs resulting from extraction or purification (last lane).

heat-labile sites. Nicked open plasmid DNA was separated on gels, extracted and purified by using a QIAquick Gel extraction kit from Qiagen (Westburg). After Qiagen preparation, incubation in Tris, extraction from the gel, and incubation in reaction mixture (see below) without extract, induction of nicks unrelated to radiation was determined and found to be minimal. For treatment with UVC radiation, closed circular plasmid DNA was irradiated at a dose rate of $5 \mathrm{~J} / \mathrm{m}^{2} \mathrm{~s}^{-1}$ in a Stratalinker 2400 (Stratagene, La Jolla, CA).

\section{DNA Repair Assay}

Repair of single-stranded DNA breaks induced by ionizing radiation was performed and analyzed essentially as described previously (25). In pilot studies, different DNA concentrations and cell extract concentrations were applied to a $50-\mu 1$ reaction mixture [50 $\mathrm{m} M$ Hepes- $\mathrm{KOH}, \mathrm{pH} 7.8$, $10 \mathrm{~m} M \mathrm{MgCl}_{2}, 70 \mathrm{~m} M \mathrm{KCl}, 3 \%$ glycerol, $1 \mathrm{~m} M$ dithiotreitol (DTT), 20 $\mu \mathrm{g} / \mathrm{ml}$ bovine serum albumin (BSA), $4 \mathrm{~m} M$ ATP, $50 \mu M$ dNTP, $80 \mathrm{~m} M$ phosphocreatine, $5 \mu \mathrm{g}$ creatine phosphokinase, and $2 \mathrm{~m} M$ NAD]. Control samples with no extract or no ATP in the reaction were included in the experiments. These samples did not differ from the 0 min repair samples. Repair of unirradiated DNA (cc) was complete in less than 5 min. To monitor repair synthesis, $740 \mathrm{kBq}\left[\alpha-{ }^{32} \mathrm{P}\right] \mathrm{dGTP}(111 \mathrm{TBq} / \mathrm{mmol})$ was added to the reaction mixture with lowered dGTP concentrations $(5 \mu M)$. DNA and cell extract concentrations are given in the text. For repair assays with extracts from MEFs or EM9/AA8, $100 \mathrm{ng}$ of DNA and 25 $\mu \mathrm{g}$ extract were typically added to the reaction. At indicated times, the reaction, which was performed at $30^{\circ} \mathrm{C}$ in a water bath, was stopped by the addition of sodium dodecyl sulfate (SDS) to a final concentration of $0.6 \%$ and $20 \mathrm{~m} M$ EDTA, then followed by the RNase and proteinase $\mathrm{K}$ treatment. DNA was purified and recovered by using a QIAquick Nucleotide removal kit from Qiagen (Westburg). Repair assays of UVC-irradiated plasmids were performed essentially as described above with $[\alpha-$ $\left.{ }^{32} \mathrm{P}\right] \mathrm{dATP}$ added to the reaction mixture.

Open circular and closed circular forms of the plasmid were resolved by electrophoresis at $20^{\circ} \mathrm{C}$ through a $1 \%$ agarose gel containing ethidium bromide to analyze DNA repair activity. DNA was visualized after additional SYBR Green I staining with a Fluor Chem Imaging System (Alpha Innotech Corporation). Due to the additional staining with SYBR green, low amounts of DNA were detectable. For nucleotide incorporation analysis, the gel was dried under vacuum after taking images for total DNA analysis by SYBR Green and exposed on a Fuji Imaging Plate. Bands were visualized using a FUJIFILM FLA-3000 Fluorescent Image
Analyzer. Quantification of SYBR Green or [ $\left.{ }^{32} \mathrm{P}\right] \mathrm{dGMP} /\left[{ }^{32} \mathrm{P}\right] \mathrm{dAMP}$ incorporation was performed using the Phoretix 1D Software (Shimadzu).

\section{RESULTS}

\section{Ionizing Radiation-Induced DNA Damage Repair Assay}

The repair assay used in this study was originally described by Satoh and Lindahl $(19,26)$ and later adapted by Vodenicharov and colleagues (25). Irradiated nicked DNA was extracted from the gel and added to cell extracts from A549 (human adenocarcinoma) cells. Extraction and purification from the gel induced few additional nicks in the irradiated DNA, as shown in Fig. 1. After different repair intervals, the DNA was then separated on an agarose gel containing ethidium bromide. Fully repaired DNA appears in the supercoiled DNA band (cc) not present before (Fig. 1, last lane) or without repair (no extract or no ATP control).

We first optimized repair conditions and assessed repair parameters. The purified nicked substrate DNA (oc) is converted to closed circular plasmid DNA (cc), increasing with repair time and reaching half maximum values in about 30 min (Fig. 2A). Linear plasmid DNA intensities were very low and did not change with time, indicating no significant increase in DSB formation (or repair) due to extract incubation. Repair was determined by the ratio of the intensity of the repaired closed circular DNA band (cc) relative to the nicked DNA band (oc), with this ratio reflecting repair efficiency (corrected for any DNA loading variations). Differences in binding efficiency of the fluorescent dye in closed circular compared to open circular DNA was accounted for by a factor of 1.6 for the closed circular DNA. We analyzed extracts from human A549 cells that were transduced with a retroviral vector expressing the 14-kDa $\mathrm{N}$-terminal DNA binding domain of DNA polymerase $\beta$ (polßDN) compared to empty vector controls. Maximum repair with $50-70 \%$ of the nicked DNA (oc) converted into closed circular DNA (cc) was typically achieved after 60 min incubation (Fig. 2A and B).

\section{Decreased Repair of Radiation-Induced DNA Damage in Cell Extracts with a Dominant Negative to DNA Polymerase $\beta$}

We next determined repair efficiencies with varying substrate DNA concentrations (Fig. 3). Figure 3A demonstrates that repair was saturated at high DNA concentrations $(>50$ $\mathrm{ng} / 100 \mu \mathrm{g}$ extract), with similar repair values for extracts containing the pol $\beta$ DN compared to empty vector controls. We observed less repaired closed circular DNA in the polDN extracts at lower DNA concentrations (Fig. 3A). With less than $50 \mathrm{ng}$ DNA/100 $\mu \mathrm{g}$ extract, most of the damaged DNA (up to $90 \%$ ) was repaired, with little unrepaired (oc) DNA (Fig. 3B and C). Further experiments with different extract preparation batches confirmed repair deficiencies in the extracts containing polDN, but only at lower 
A

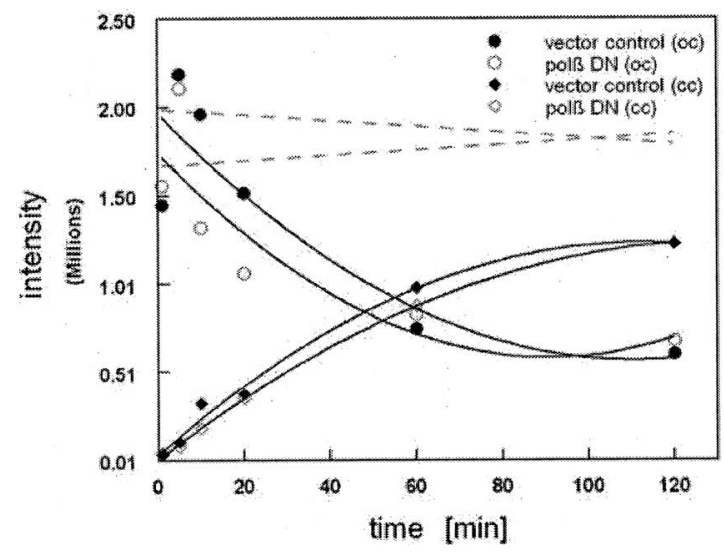

B

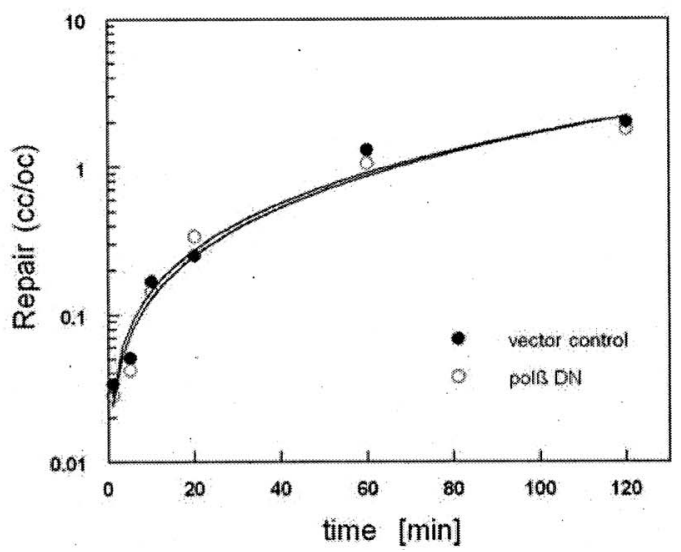

FIG. 2. In vitro repair assay of ionizing radiation damage. Panel A: Intensity of repaired supercoiled (cc) and open circular (oc) band as a function of repair time. Two hundred nanograms of irradiated plasmid DNA was applied to $100 \mu \mathrm{g}$ of A549-LZRS (closed circles) or A549-polßDN (open circles) cell extracts. Decrease in damaged nicked DNA (oc, circles) is accompanied by an increase in repaired DNA (cc, diamonds) with increasing repair time. The dotted lines indicate the additive values of both bands. Panel B: Repair as assessed by the ratio of repaired DNA (cc) band intensities to unligated open circular DNA (oc) band intensities to account for potential loading differences.

DNA concentrations, with concomitantly higher fractions of nicked DNA being repaired. Levels of XRCC1 were similar in both extracts, although the extracts containing polßDN showed slightly higher wild-type pol $\beta$ expression (Fig. 3D).

We hypothesized that the polßDN protein will bind to lesions in the DNA, thereby inhibiting their recognition and/or blocking access by wild-type pol $\beta$. Repair activity of the wild-type enzyme on nonblocked lesions is not expected to change, consequently showing normal repair efficiencies. Repair block or inhibition of the polßDN-bound DNA fraction will be detectable only when repair is nearly complete, thus exposing the unrepaired DNA fraction. The observed repair efficiency dependence (shown at different DNA concentrations) is consistent with this idea. Since low DNA concentrations were only just visible after gel electrophoresis, subsequent experiments were performed at higher DNA and cell extract amounts but at similar ratios (10 ng DNA/100 $\mu \mathrm{g}$ protein extract) (Fig. 4). By the addition of radioactive nucleotides to the repair reaction mixture, we analyzed changes in incorporation rates.

Figure 4A demonstrates the repair capacity determined by fluorescence intensities (left panel) or by autoradiography (right panel). Repair efficiencies (intensities of closed circular/open circular) were reduced in extracts containing polßDN in both measurements. Dividing intensity values derived from the autoradiography analysis (monitoring radioactive nucleotide incorporation) by the fluorescence intensity values (derived after SYBR Green staining of the same gel prior exposure for autoradiography) of the same band, provided a relative determination of incorporation rates (arbitrary units) of radioactive nucleotides. Fluorescence intensity values have been corrected by a factor of 1.6 for supercoiled plasmid DNA. The ${ }^{32} \mathrm{P}$ incorporation rates did not differ significantly in the unrepaired nicked (oc) DNA but were significantly increased in the repaired (cc) DNA of extracts containing polßDN (Fig. 4B).

The repair curves for control and pol $\beta D N$ extracts were nicely replicated in the experiments shown in Figs. 2 and 3 , indicating equal extract quality. In addition, several independent cell extract preparations from different cell passages were analyzed to exclude variations in cell extract preparation being responsible for the observed differences in repair. PolßDN cell extracts repeatedly showed lower repair efficiency compared with vector control cell extracts (Fig. 4C, extract A and B). Repair efficiencies varied in the individual experiments and in the different extract preparations, but on average, repair values of control extracts relative to extracts containing pol $\beta D N$ were increased by a factor of 1.89 (SD 0.43 with $n=5$ independent experiments). Although the difference in repair between the extracts was modest (85\% compared to $92 \%$ of the DNA repaired), it was significantly different $(P=0.043$, Student's paired $t$ test, or $P=0.031$ by a one-sided sign test). These data demonstrate repair inhibition on a fraction of radiationdamaged plasmid DNA in cell extracts containing a dominant negative of DNA polymerase $\beta$, suggesting that radiosensitization observed in the cell lines resulted from inhibition of SSB repair.

\section{XRCC1-Deficient Cell Extracts Display Reduced Repair of Radiation-Induced DNA Damage}

The involvement of XRCC1 in repair of damage induced by ionizing radiation has been evident since the discovery of radiation-sensitive XRCC1 mutant or deficient cells. Whitehouse et al. (6) showed significant reduction in repair of oligonucleotides with single-strand nicks in cell extracts 
A

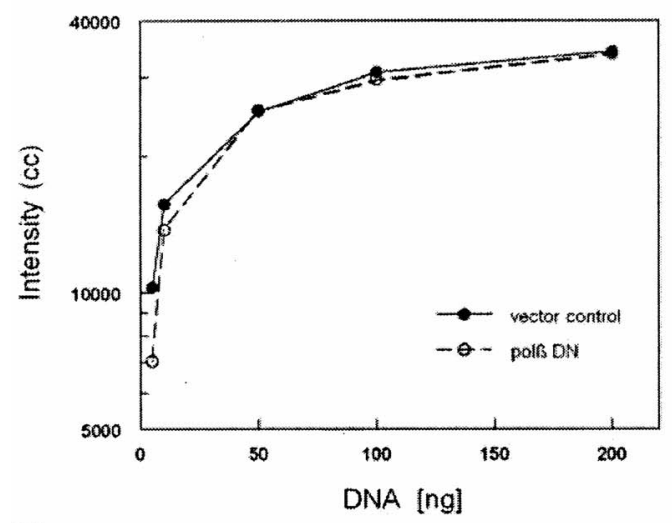

B

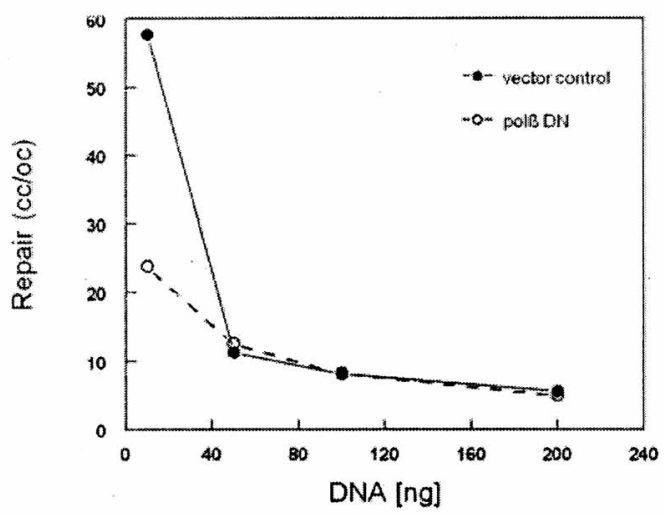

C

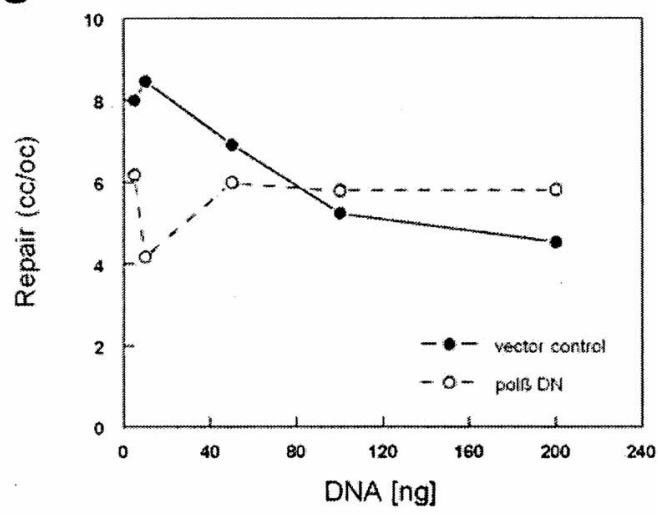

D derived from EM9 cells deficient in XRCC1 compared to the wild-type controls. Here we analyzed repair efficiency of genuine radiation DNA damage and observed a dramatic reduction of repair capacity in these extracts. The conversion of irradiated, nicked open circular DNA (oc) to closed circular DNA (cc), the repaired product as a function of repair time, is shown in Fig. 5A. Repair efficiency was determined as the ratio of the fluorescence intensity of the (cc) band to the (oc) band. A threefold difference in repair efficiencies of XRCC1-deficient extracts compared with wild-type extracts was observed in these experiments, confirming BER/SSB repair specificity of the in vitro assay used here.

When analyzed by autoradiography intensity values (Fig. 5B), again determined as the ratio of open circular/close circular DNA to correct for possible loading differences, the reduction in repair was even more pronounced. The reduced repair capacity is probably due to reduced ligation activity in the extracts, and our data show that repair of radiation-induced SSBs in this in vitro assay is highly dependent on XRCC1/Ligase III activity.

\section{DNA Damage Repair Deficiency after Exposure to Ionizing Radiation in Cell Extracts Lacking DNA Polymerase $\beta$}

Our studies with dominant negative expressing cells indicated an interference in repair of radiation-induced lesions, although it was not clear if the block of alternative pathways had a bigger impact on repair capacity than the block of the wild-type enzyme itself. Here we questioned whether pol $\beta$-deficient cells and their extracts exhibited reduced repair capacity in our in vitro assay for ionizing radiation damage. Less conversion to closed circular plasmid DNA was observed in cell extracts derived from mouse embryonic pol $\beta$ knockout fibroblasts ( $\operatorname{pol} \beta \mathrm{KO}$ ) compared to their polß-proficient counterparts (WT) (Fig. 6). Quantification showed a twofold reduction in the open circular/ closed circular conversion rate in the pol $\beta$-deficient cells (Fig. 6B-D). This reduction was significant in all individual experiments, as determined by regression analysis. A total of nine individual experiments were performed with a 40min repair time; repair was lower by a factor of 0.63 (stan-

$\leftarrow$

FIG. 3. Repair inhibition of the pol $\beta D N$ protein appears at higher repair rates. Five to $200 \mathrm{ng}$ of irradiated plasmid DNA (oc) was applied to $100 \mu \mathrm{g}$ of A549 vector control (closed circles) or A549-polßDN (open circles) cell extracts for $60 \mathrm{~min}$. Panel A: Intensity of the repaired DNA (cc) decreased in the A549-polßDN derived extracts at lower input DNA values. Panel B: Repair was determined by the ratio of supercoiled repaired DNA (cc) band to nicked open circular plasmid DNA (oc). Repair rates increased substantially in the vector controls (closed circles) vector control extracts with less than $50 \mathrm{ng}$ DNA in $60 \mathrm{~min}$ but not in the extracts containing polßDN (open circles). Panel C: As for panel B, but with a different extract and DNA preparation. Panel D: Western blot analyses for XRCC1 and pol $\beta$ expression of the polßDN containing and empty vector control extracts with tubulin as loading control. 

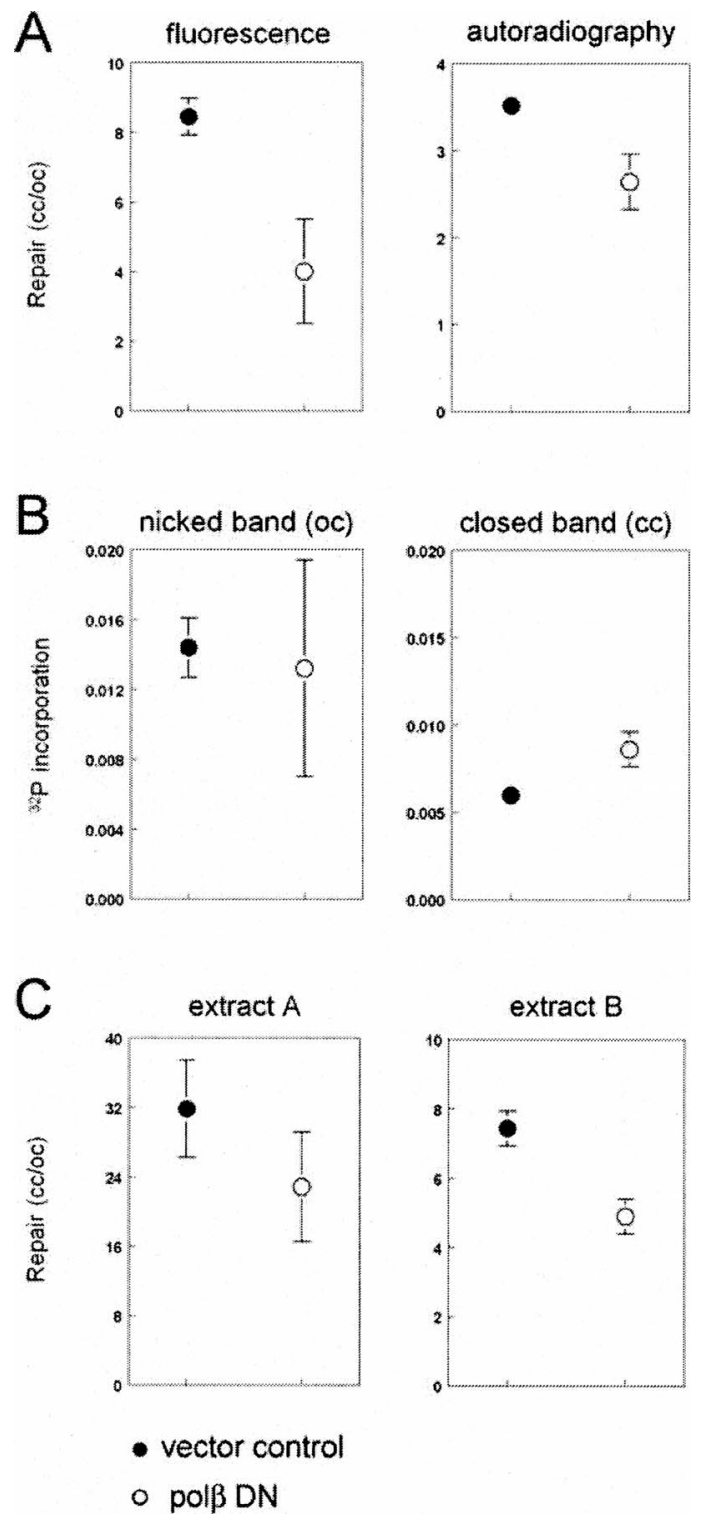

FIG. 4. Repair inhibition by the polßDN. Panel A: Repair of nicked irradiated DNA is decreased in extracts containing polßDN from A549polßDN cells. Repair (100 ng DNA, $1000 \mu \mathrm{g}$ extract, 60 min incubation) was assessed from the fluorescence intensities of the closed (cc) and open (oc) circular bands after SYBR green staining (left panel) and autoradiography (right panel). Values are from triplicate assays performed in parallel, with errors being 1 SD. Panel B: Incorporation rates (arbitrary units) were calculated from autoradiography intensity values relative to SYBR green fluorescence intensities from the same bands of the gel in either the nicked unrepaired (oc) (left panel) or closed circular repaired (cc) bands (right panel). Values are from triplicate assays, with errors being $1 \mathrm{SD}$ (error in vector control too small to be visible). Panel C: Repair was assessed in two separate extracts preparations A and B of polßDN and empty vector control cells with $25 \mathrm{ng}$ of irradiated nicked DNA and $250 \mu \mathrm{g}$ of extract. Values are from triplicate assays; errors are $1 \mathrm{SD}$. Although repair efficiency differed between the extracts, repair inhibition in extracts containing pol $\beta D N$ was observed in both.

dard deviation $0.13, n=9$ ) in polß-deficient extracts. In contrast, ratios determined by autoradiography did not differ (factor of 0.94, standard deviation $0.11, n=9$ ). Repair efficiencies of DNA polymerase $\beta$-deficient cells remained low in comparison to controls with increasing extract concentrations (Fig. 6D).

The reduction in repair was not as large as with extracts from XRCC1-deficient cells, indicating a substantial contribution of XRCC1-dependent but pol $\beta$-independent processes. In a separate study, we found that radiosensitization by the polßDN was XRCC1-dependent and largely pol $\beta$ independent (22).

Interestingly, and in contrast to XRCC1-deficient cells, incorporation rates were increased in the circular repaired plasmid DNA of pol $\beta$-deficient extracts in relation to the nicked DNA, thus resulting in equal repair values when determined by autoradiography (Fig. 6B-D, right panel). As already seen in the agarose gel image (Fig. 6A), less DNA incorporated higher amounts of radioactive nucleotides, indicating longer stretches of newly synthesized DNA during repair by extracts deficient in DNA polymerase $\beta$ compared to wild-type. Determination of the relative incorporation rates (ratio of autoradiography intensity values to fluorescence intensity values of the same band on the same gel) (Fig. 7A) demonstrated that the closed circular DNA repaired by the pol $\beta$-deficient extracts showed higher ${ }^{32} \mathrm{P}$ nucleotide incorporation (up to two- to threefold), while the incorporation rate on unrepaired DNA (open circular band) remained similar. In pol $\beta$-deficient extracts, with less DNA repaired and an increased incorporation in the repaired fraction only, repair ratios (closed circular/open circular) determined by autoradiography were equal to the wild-type. These data show that other polymerases present in the extract cannot fully replace DNA polymerase $\beta$ but are capable of repairing a significant amount of the damages present in the DNA. About $30-50 \%$ of the lesions repaired in pol $\beta$-proficient extracts appear to be repaired by alternative polymerases. Since repair efficiencies could have changed independent of DNA polymerase $\beta$ status, e.g. reflecting differences in extract qualities, we assessed repair of UV-radiation-induced lesion in the extracts analyzed for SSB repair. Plasmid DNA was irradiated with UVC light, and nucleotide excision repair activity was then monitored by incorporation of radioactive nucleotides. Figure 7C shows similar repair capacities on UVC-irradiated plasmid DNA in both extracts, demonstrating equal extract qualities. We conclude that the repair deficiency observed on irradiated DNA is specific to ionizing radiation-induced damage. The data presented here showed a decreased repair capacity of extracts deficient in pol $\beta$, underlining the recently reported hypersensitivity to ionizing radiation when cells are confluent (18).

\section{DISCUSSION}

The data presented here demonstrate the involvement of DNA polymerase $\beta$-dependent pathways in repair using an in vitro repair assay employing genuine ionizing radiationinduced lesions. Exposure to pol $\beta$-deficient extracts resulted in less repair in these assays. However, considerable re- 


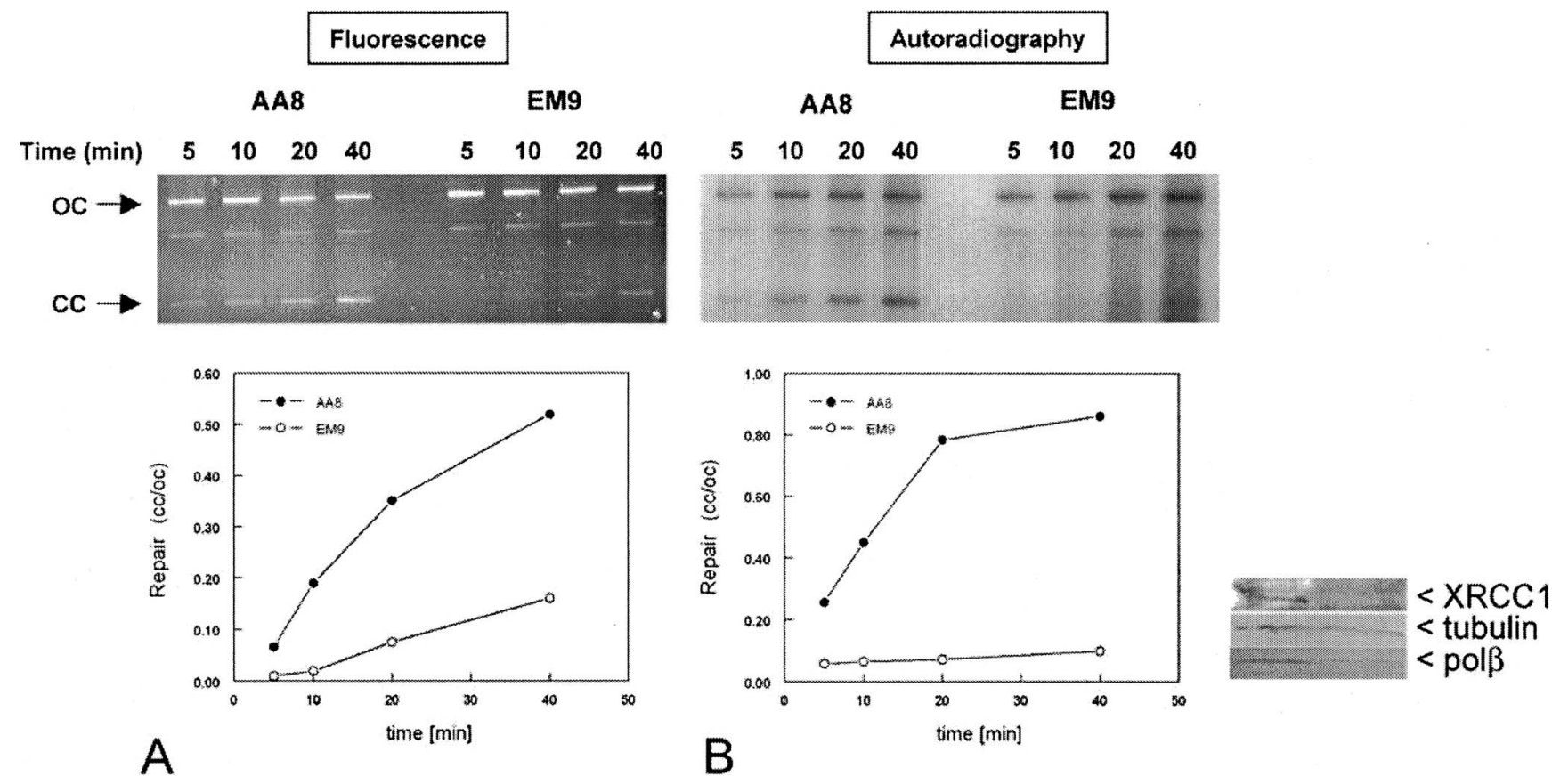

FIG. 5. Repair deficiency in XRCC1-deficient cell extracts. Nicked irradiated DNA (100 ng) was exposed to (25 $\mu \mathrm{g}$ ) extracts from EM9 (XRCC1deficient) and AA8 parental (XRCC1 wild-type) cells. Fluorescence images were taken after SYBR green staining for total DNA determination and autoradiographic images of the same gel. The closed circular/oc values from the images shown are plotted (AA8, closed circles; EM9, open circles), with A being calculated from fluorescence intensities and B from autoradiography intensities. A representative time course of three experiments is shown (one sample per point).

pair still occurred compared to XRCC1-deficient conditions, indicating significant involvement of alternative pathways.

The repair parameter measured here, appearance of a closed circular DNA band, is composed of two related processes: successfully completed BER after AP-endonuclease incision at several base lesions and SSB repair at the initial radiation-induced nick, and possibly at nonprocessed or unligated BER intermediates. Initiation of repair will lead to additional nicks, a consequence of the glycosylase and/or $\mathrm{AP}$ endonuclease action, at the site of a base lesion. Conversion to closed circular DNA will be possible only after ligation of these base excision repair intermediates and most importantly only after repair and ligation of the original initial radiation-induced nick. Addition of purified irradiated nicked (oc) DNA to the repair reaction mixture ensures that the appearance of closed circular DNA derived after repair of the original radiation-induced nicks (primary and secondary).

Repair inhibition of the polßDN was observed at repair rates above DNA saturation values, with no corresponding changes in the saturation levels. A possible explanation would be that only a fraction of the damaged DNA was left unrepaired in the extracts containing polßDN and that high repair values are needed to expose this "unrepairable" fraction among the repairable breaks. This is consistent with the idea that the polßDN physically blocks access of repair proteins to the lesion by binding rather than altering enzymatic activities. A possible alternative mechanism is an indirect effect on repair, e.g. through sequestration of proteins important for repair (27) or alterations of their activity. The difference in repair was reproducible and significant, and, together with the observed radiosensitization seen in polßDN-expressing cells, the data indicate interference in SSB repair leading to increased total damage. This in turn leads to lethality (manuscript in preparation). A direct involvement of the pol $\beta D N$ in repair processes of radiation-induced damage cannot be concluded from the repair assays applied here. Mechanisms of interference will have to be addressed by assays applying purified proteins on specific lesions. However, we showed that extracts derived from polßDN-expressing cells exhibited repair deficiencies that probably caused the observed radiosensitization.

Although there was substantial radioactive nucleotide incorporation in the nicked (supposedly unrepaired) DNA, we did not observe differences in this incorporation whether or not polßDN was present in the extract. Differences were visible, however, in the repaired closed circular DNA band, indicating that although fewer molecules were repaired, each repair event was apparently associated with more nucleotides, a feature of long patch repair. This could result from a switch in pathway choice after a short patch repair attempt failed or could indicate a preference of the pol $\beta D N$ for a particular fraction of lesions: Lesions that preferentially use long patch repair might not be affected by the pol $\beta D N$, thereby leading to an increased incorporation rate in the repaired fraction. 
A

Fluorescence

WT

Pol $\beta$ KO

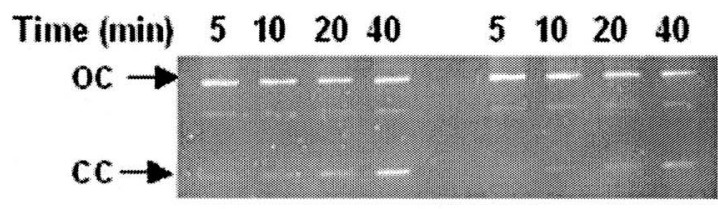

B

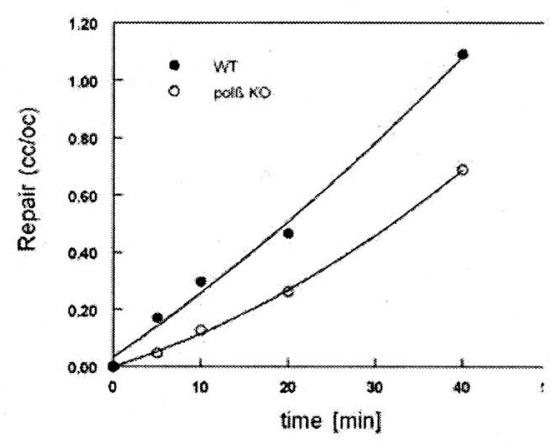

C

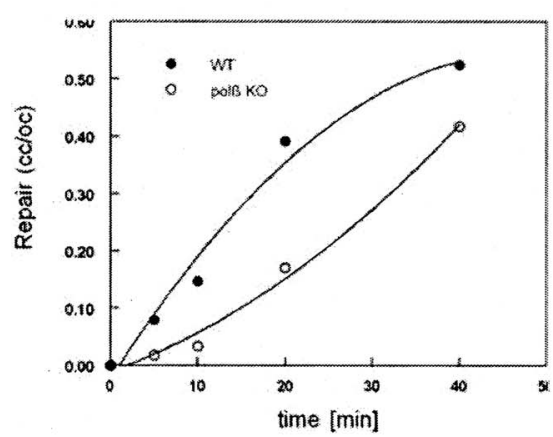

D

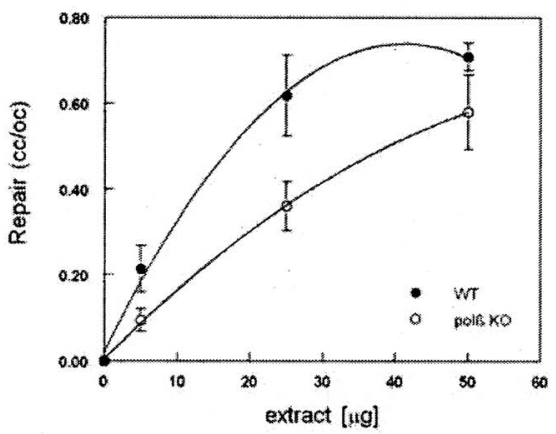

\section{Autoradiography}

WT

Pol BKo

$\begin{array}{llllllll}5 & 10 & 20 & 40 & 5 & 10 & 20 & 40\end{array}$
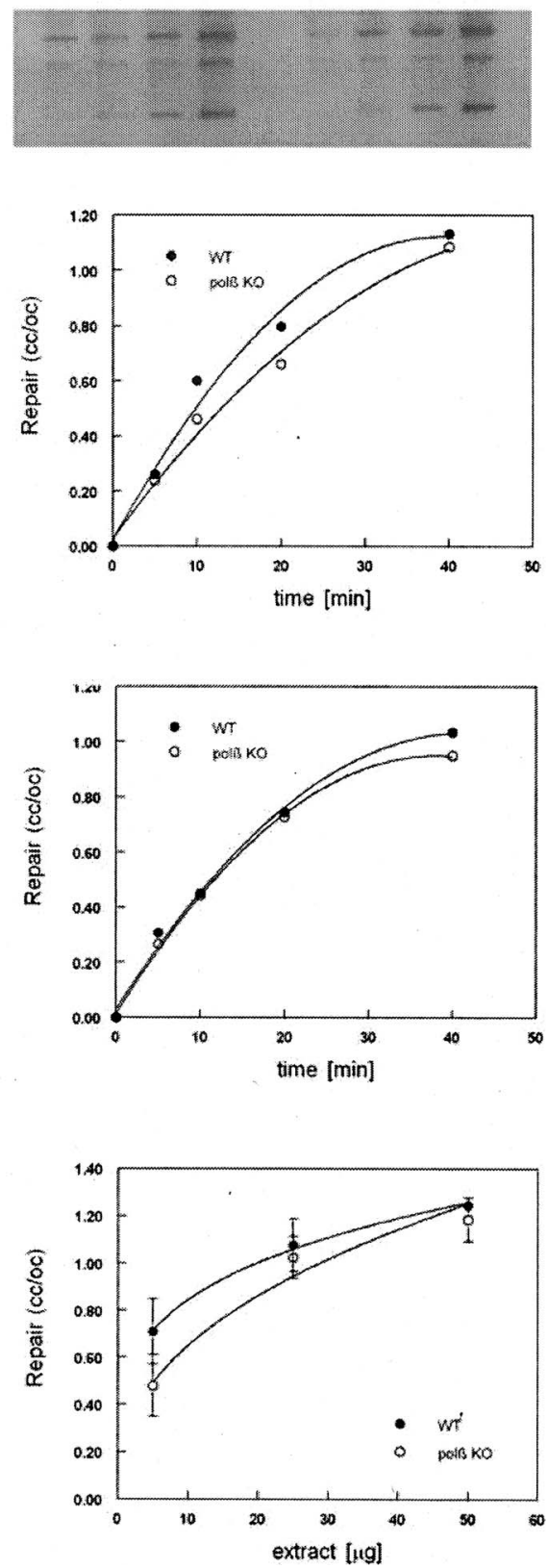

FIG. 6. Decreased repair in DNA polymerase $\beta$-deficient extracts. Panel A: Nicked irradiated DNA (100 ng) was exposed to extracts $(25 \mu \mathrm{g})$ from polß-deficient cells (Pol $\beta K O)$ and its corresponding DNA polymerase-proficient wild-type cell line (WT). Fluorescence images were taken after SYBR green staining for total DNA and autoradiographic images of the same gel for radioactive nucleotide incorporation. Panel B: cc/oc values for the images shown above (WT, closed circles; polßKO, open circles) determined from fluorescence (left panel) or autoradiographic intensities of the same gel (right panel). Two independent experiments are shown in panels B and C (one sample per point). Panel D: Repair dependence on extract concentration. One hundred nanograms of irradiated nicked plasmid DNA (oc) was incubated for 40 min with varying extract concentrations. Values are from triplicate assays with errors being $1 \mathrm{SD}$.

The repair rate was significantly reduced in extracts from pol $\beta$-deficient cells. Similar to the polßDN repair assays, repaired closed circular DNA showed higher incorporation values in the pol $\beta$-deficient background, indicating a stronger involvement of pathways incorporating more nucleo- tides (long patch repair) at successfully repaired sites. Long patch repair results in incorporation of up to 10 nucleotides, and with one of four nucleotides being radioactive, this fits well with the observed increase of 2.5 , assuming that a considerable fraction of the repair in the pol $\beta$-proficient 
A
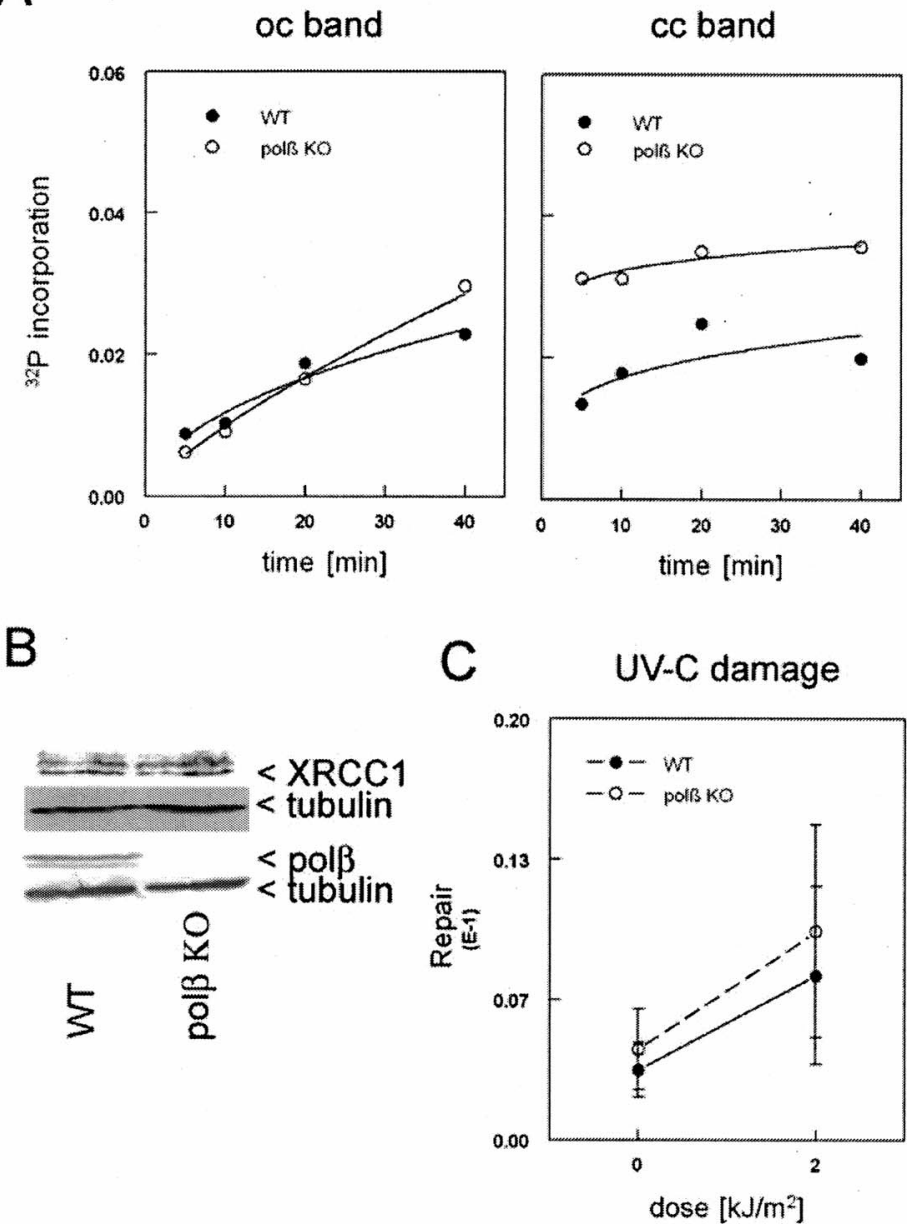

FIG. 7. Repair efficiency in DNA polymerase $\beta$-deficient extracts. Panel A: Incorporation rates are increased in closed circular DNA (cc) repaired by polß-deficient extracts. Incorporation rates (arbitrary units) were calculated from autoradiography intensities relative to SYBR green fluorescence intensities in the nicked unrepaired (oc) or closed circular repaired band (cc). Panel B: Western blot analysis for XRCC1 and pol $\beta$ expression in the extracts. Panel C: UVC-radiation damage repair is not altered in DNA polymerase $\beta$-deficient extracts. Quality of the extracts was determined by BER-unrelated repair of UVC-irradiated $\left(2 \mathrm{~kJ} / \mathrm{m}^{2}\right)$ plasmid DNA by measurement of radioactive nucleotide incorporation relative total DNA amount as determined by fluorescence intensity. Values are the average of five independent experiments with errors being $1 \mathrm{SD}$.

controls is repaired by short patch. Consistent with this idea, Biade et al. (24) described PCNA-dependent repair of abasic sites in pol $\beta$-deficient extracts on circular DNA, with repair on linear DNA observed only when proficient in $\operatorname{pol} \beta$.

Use of long patch might depend on the initial damage encountered (28-31) and its context within clustered damage $(32,33)$. Finalization of long patch repair should have been unaffected by the Ligase III status. Unlike the situation with polßDN or in DNA polymerase $\beta$-deficient cell extracts, long patch repair did not contribute significantly to repair of the initial SSBs in XRCC1-deficient extracts, underlining its critical role in initiating SSB repair (short or long), as described previously $(6,34)$. The majority of lesions remained unrepaired with these extracts, indicating that XRCC1/Ligase III proteins are essential for repairing initial radiation damage. This is partly a consequence of the lack of ligation by Ligase III but might also indicate an involvement of XRCC1 in long patch, since in these extracts and in contrast to the pol $\beta$-deficient extracts no alternative repair (with higher radioactive nucleotide incorporation rates) was measurable.

In turn it also demonstrates a significant participation of polß-independent but XRCC1-dependent pathways in repair of ionizing radiation damage. This is consistent with conclusions from the cellular data of Fan et al. (35) and our own observation that the polßDN did not radiosensitize XRCC1-deficient cells (22). In line with the cellular data and the data of Caldecott et al. and others $(6,34,36,37)$, it suggests a critical role for XRCC1 at initial steps in SSB repair, stabilizing the lesion and enabling access by singlestrand end-modifying enzymes and polymerases.

In addition to single SSB lesions, ionizing radiation also typically induces lesions in proximity, referred as to clustered damage. Repair inhibition at clustered lesions might promote the formation of DSBs (32). However, under the radiation conditions used here, the induction of clustered lesions is minimal (38). Consistent with this, we saw little DSB induction in the assays described here. Since interference in SSB repair was observed, future experiments will address the contribution to DSB formation at clustered lesion as a consequence of the interference.

Interestingly, pol $\beta D N$ expression results in a significant reduction in survival after ionizing radiation, consistent with the observed repair inhibition, whereas deficiency in pol $\beta$ has an effect only when the cells are nonproliferating. Our data suggest that repair is slowed down but not completely blocked in the pol $\beta$-deficient background, allowing redundant repair activities (such as replication-associated repair) to act. Such activities are not present in the in vitro assay. Alternatively, lesions occupied by polßDN might differ in cytotoxicity from the initial lesion or in its persistence. Truncated DNA polymerase $\beta$ proteins have been found in many cancer cell lines $(39,40)$, implying that their BER/SSB repair inhibitory action adds to their oncogenic potential (4143). In addition, tumors carrying such mutations may have increased radiosensitivity. DNA polymerase $\beta$ inhibitors resulting in synthesis-inactive but DNA-binding proficient pol $\beta$ proteins, analogous to the polßDN, might be worth testing as potential radiosensitizers.

Taken together, our data suggest a critical role of DNA polymerase $\beta$ in SSB repair and BER of ionizing radiation-induced damage. This translates into increased killing when devoid of backup repair or if persistent blocks of redundant polymerases occur. Repair inhibition was less than that seen in XRCC1-deficient extracts, demonstrating involvement of XRCC1-dependent, DNA polymerase $\beta$ independent repair pathways. Increased nucleotide incor- 
poration suggests that long patch polymerases are capable of repairing a considerable fraction of the damage in the presence of XRCC1.

\section{ACKNOWLEDGMENTS}

We thank Michael Hauptmann for help with the statistical analysis and the Dutch Cancer Society for partial financial support (grant NKI 20022589).

Received: July 10, 2006; accepted: February 27, 2007

\section{REFERENCES}

1. G. Slupphaug, B. Kavli and H. E. Krokan, The interacting pathways for prevention and repair of oxidative DNA damage. Mutat. Res. 531, 231-251 (2003).

2. G. L. Dianov, R. Prasad, S. H. Wilson and V. A. Bohr, Role of DNA polymerase beta in the excision step of long patch mammalian base excision repair. J. Biol. Chem. 274, 13741-13743 (1999).

3. M. Stucki, B. Pascucci, E. Parlanti, P. Fortini, S. H. Wilson, U. Hubscher and E. Dogliotti, Mammalian base excision repair by DNA polymerases delta and epsilon. Oncogene 17, 835-843 (1998).

4. A. E. Tomkinson, L. Chen, Z. Dong, J. B. Leppard, D. S. Levin, Z. B. Mackey and T. A. Motycka, Completion of base excision repair by mammalian DNA ligases. Prog. Nucleic Acid Res. Mol. Biol. 68, 151-164 (2001)

5. L. H. Thompson, K. W. Brookman, N. J. Jones, S. A. Allen and A. V. Carrano, Molecular cloning of the human XRCC1 gene, which corrects defective DNA strand break repair and sister chromatid exchange. Mol. Cell Biol. 10, 6160-6171 (1990).

6. C. J. Whitehouse, R. M. Taylor, A. Thistlethwaite, H. Zhang, F. Karimi-Busheri, D. D. Lasko, M. Weinfeld and K. W. Caldecott, XRCC1 stimulates human polynucleotide kinase activity at damaged DNA termini and accelerates DNA single-strand break repair. Cell 104, 107-117 (2001)

7. K. W. Caldecott, XRCC1 and DNA strand break repair. DNA Repair (Amst.) 2, 955-969 (2003).

8. G. L. Dianov, K. M. Sleeth, I. I. Dianova and S. L. Allinson, Repair of abasic sites in DNA. Mutat. Res. 531, 157-163 (2003).

9. I. I. Dianova, K. M. Sleeth, S. L. Allinson, J. L. Parsons, C. Breslin, K. W. Caldecott and G. L. Dianov, XRCC1-DNA polymerase beta interaction is required for efficient base excision repair. Nucleic Acids Res. 32, 2550-2555 (2004).

10. S. H. Wilson, Mammalian base excision repair and DNA polymerase beta. Mutat. Res. 407, 203-215 (1998).

11. G. L. Dianov, T. Thybo, I. I. Dianova, L. J. Lipinski and V. A. Bohr, Single nucleotide patch base excision repair is the major pathway for removal of thymine glycol from DNA in human cell extracts. J. Biol. Chem. 275, 11809-11813 (2000).

12. A. Klungland and T. Lindahl, Second pathway for completion of human DNA base excision-repair: Reconstitution with purified proteins and requirement for DNase IV (FEN1). EMBO J. 16, 33413348 (1997).

13. J. Parsons, I. Dianova and G. Dianov, APE1-dependent repair of DNA single-strand breaks containing 3 '-end 8-oxoguanine. Nucleic Acids Res. 33, 2204-2209 (2005).

14. Y. J. Xu, E. Y. Kim and B. Demple, Excision of C-4'-oxidized deoxyribose lesions from double-stranded DNA by human apurinic/ apyrimidinic endonuclease (Ape1 protein) and DNA polymerase beta. J. Biol. Chem. 273, 28837-28844 (1998).

15. M. Miura, H. Watanabe, K. Okochi, T. Sasaki and H. Shibuya, Biological response to ionizing radiation in mouse embryo fibroblasts with a targeted disruption of the DNA polymerase beta gene. Radiat. Res. 153, 773-780 (2000).

16. R. W. Sobol, J. K. Horton, R. Kuhn, H. Gu, R. K. Singhal, R. Prasad,
K. Rajewsky and S. H. Wilson, Requirement of mammalian DNA polymerase-beta in base-excision repair. Nature 379, 183-186 (1996).

17. C. Vens, E. Dahmen-Mooren, M. Verwijs-Janssen, W. Blyweert, L. Graversen, H. Bartelink and A. C. Begg, The role of DNA polymerase beta in determining sensitivity to ionizing radiation in human tumor cells. Nucleic Acids Res. 30, 2995-3004 (2002).

18. C. Vermeulen, M. Verwijs-Janssen, P. Cramers, A. C. Begg and C. Vens, Role for DNA polymerase beta in response to ionizing radiation. DNA Repair (Amst.) 6, 202-212 (2006).

19. M. S. Satoh and T. Lindahl, Role of poly(ADP-ribose) formation in DNA repair. Nature 356, 356-358 (1992).

20. Y. Matsumoto, Base excision repair in mammalian cells. Methods Mol. Biol. 314, 365-375 (2006).

21. I. Hofland, B. Ramakers, A. C. Begg and C. Vens, Rapid fluorescence ratio assay for detecting changes in radiosensitivity. Radiat. Res. 157 734-739 (2002).

22. S. Neijenhuis, A. C. Begg and C. Vens, Radiosensitization by a dominant negative to DNA polymerase beta is DNA polymerase betaindependent and XRCC1-dependent. Radiother. Oncol. 76, 123-128 (2005).

23. M. Tanaka, J. S. Lai and W. Herr, Promoter-selective activation domains in Oct-1 and Oct-2 direct differential activation of an snRNA and mRNA promoter. Cell 68, 755-767 (1992).

24. S. Biade, R. W. Sobol, S. H. Wilson and Y. Matsumoto, Impairment of proliferating cell nuclear antigen-dependent apurinic/apyrimidinic site repair on linear DNA. J. Biol. Chem. 273, 898-902 (1998).

25. M. D. Vodenicharov, F. R. Sallmann, M. S. Satoh and G. G. Poirier, Base excision repair is efficient in cells lacking poly(ADP-ribose) polymerase 1. Nucleic Acids Res. 28, 3887-3896 (2000).

26. M. S. Satoh, G. G. Poirier and T. Lindahl, NAD(+)-dependent repair of damaged DNA by human cell extracts. J. Biol. Chem. 268, 54805487 (1993).

27. L. Wang, N. Bhattacharyya, D. M. Chelsea, P. F. Escobar and S. Banerjee, A novel nuclear protein, MGC5306 interacts with DNA polymerase beta and has a potential role in cellular phenotype. Cancer Res. 64, 7673-7677 (2004).

28. E. Dogliotti, P. Fortini, B. Pascucci and E. Parlanti, The mechanism of switching among multiple BER pathways. Prog. Nucleic Acid Res. Mol. Biol. 68, 3-27 (2001).

29. M. M. Greenberg, Y. N. Weledji, K. M. Kroeger and J. Kim, In vitro replication and repair of DNA containing a $\mathrm{C}^{\prime}$ '-oxidized abasic site. Biochemistry 43, 15217-15222 (2004).

30. U. Sattler, P. Frit, B. Salles and P. Calsou, Long-patch DNA repair synthesis during base excision repair in mammalian cells. EMBO Rep. 4, 363-367 (2003).

31. J. S. Sung, M. S. DeMott and B. Demple, Long-patch base excision DNA repair of 2-deoxyribonolactone prevents the formation of DNAprotein cross-links with DNA polymerase beta. J. Biol. Chem. 280, 39095-39103 (2005).

32. M. E. Lomax, S. Cunniffe and P. O'Neill, Efficiency of repair of an abasic site within DNA clustered damage sites by mammalian cell nuclear extracts. Biochemistry 43, 11017-11026 (2004).

33. M. E. Lomax, S. Cunniffe and P. O'Neill, 8-OxoG retards the activity of the ligase III/XRCC1 complex during the repair of a single-strand break, when present within a clustered DNA damage site. DNA Repair (Amst.) 3, 289-299 (2004).

34. K. W. Caldecott, S. Aoufouchi, P. Johnson and S. Shall, XRCC1 polypeptide interacts with DNA polymerase beta and possibly poly (ADP-ribose) polymerase, and DNA ligase III is a novel molecular 'nick-sensor' in vitro. Nucleic Acids Res. 24, 4387-4394 (1996).

35. J. Fan, M. Otterlei, H. K. Wong, A. E. Tomkinson and D. M. Wilson, III, XRCC1 co-localizes and physically interacts with PCNA. Nucleic Acids Res. 32, 2193-2201 (2004).

36. L. H. Thompson and M. G. West, XRCC1 keeps DNA from getting stranded. Mutat. Res. 459, 1-18 (2000).

37. A. E. Vidal, S. Boiteux, I. D. Hickson and J. P. Radicella, XRCC1 
coordinates the initial and late stages of DNA abasic site repair through protein-protein interactions. EMBO J. 20, 6530-6539 (2001).

38. P. S. Hodgkins, M. P. Fairman and P. O'Neill, Rejoining of gammaradiation-induced single-strand breaks in plasmid DNA by human cell extracts: Dependence on the concentration of the hydroxyl radical scavenger, Tris. Radiat. Res. 145, 24-30 (1996).

39. N. Bhattacharyya, H. C. Chen, S. Comhair, S. C. Erzurum and S. Banerjee, Variant forms of DNA polymerase beta in primary lung carcinomas. DNA Cell Biol. 18, 549-554 (1999).

40. N. Bhattacharyya, H. C. Chen, L. Wang and S. Banerjee, Heteroge- neity in expression of DNA polymerase beta and DNA repair activity in human tumor cell lines. Gene Expr. 10, 115-123 (2002).

41. J. B. Sweasy, T. Lang, D. Starcevic, K. W. Sun, C. C. Lai, D. DiMaio and S. Dalal, Expression of DNA polymerase $\beta$ cancer-associated variants in mouse cells results in cellular transformation. Proc. Natl. Acad. Sci. USA 102, 14350-14355 (2005).

42. J. B. Sweasy, T. Lang and D. DiMaio, Is base excision repair a tumor suppressor mechanism? Cell Cycle 5, 250-259 (2006).

43. D. Starcevic, S. Dalal and J. B. Sweasy, Is there a link between DNA polymerase beta and cancer? Cell Cycle 3, 998-1001 (2004). 